\title{
Clinical effect and safety evaluation of different dosage of Rituximab combined with Cyclophosphamide in treatment of refractory immune Thrombocytopenia
}

\author{
Zhibin Wang ${ }^{1}$, Yu Ren ${ }^{2}$, Mingwei $L^{3}$, \\ Weibo Huang ${ }^{4}$, Haiying $\mathrm{Yao}^{5}$
}

\begin{abstract}
Objective: To discuss clinical effect of different dosage of rituximab combined with cyclophosphamide in treatment of refractory immune thrombocytopenia (rITP).

Method: This study was conducted at Department of Hematopathology in XX Hospital from January 2016 to January 2018. In this study. Seventy-eight patients with rITP were selected as the objects, divided into observation group (39 cases) and control group (39 cases) according to random number table. Patients in the control group were treated with conventional rituximab and cyclophosphamide, while the observation group received low-dose rituximab. The same amount of cyclophosphamide was used in the two groups. The statistics of clinical effect, recurrence rate, untoward effect and Laboratory inspection of both groups were made before and after the treatment.

Results: Compared with the control group, the total occurrence rate of side effects in the observation group decreased significantly; the level of $\mathrm{IgM}$ and $\mathrm{CD}_{2} \mathrm{O}^{+}$in the observation group also decreased significantly, while. The level of IgA, IgG, CD3+ and CD4+ rose significantly $(P<0.05)$. The differences in the level of Th1, TNF-a, IL-18 and Sc5b-9 had statistical significance before and after the treatment $(P<0.05)$.

Conclusion: Rituximab combined with cyclophosphamide has the definite curative effect on rITP. The small dosage of rituximab combined with cyclophosphamide has higher clinical safety in the treatment.
\end{abstract}

KEYWORDS: Coagulation function, Cyclophosphamide, Lymphocyte, Refractory immune thrombocytopenic purpura, Rituximab, Untoward effect.

How to cite this:

doi: https://doi.org/10.12669/pjms.36.2.1168

Wang Z, Ren Y, Li M, Huang W, Yao H. Clinical effect and safety evaluation of different dosage of Rituximab combined with Cyclophosphamide in treatment of refractory immune Thrombocytopenia. Pak J Med Sci. 2020;36(2):69-74. doi: https://doi.org/10.12669/pjms.36.2.1168

This is an Open Access article distributed under the terms of the Creative Commons Attribution License (http://creativecommons.org/licenses/by/3.0), which permits unrestricted use, distribution, and reproduction in any medium, provided the original work is properly cited.

Zhibin Wang,

2. Yu Ren,

3. Mingwei Li,

4. Weibo Huang,

5. Haiying Yao,

1-5: Department of Hematology,

Baoding First Central Hospital,

Hebei, Baoding 071000, P. R. China.

Correspondence:

Haiying Yao,

Department of Hematology,

Baoding First Central Hospital,

Hebei, Baoding 071000, P. R. China.

Email: arn627@163.com

* Received for Publication:

* Revision Received:

* Revision Accepted:
May 29, 2019

October 24, 2019

October 27, 2019

\section{INTRODUCTION}

Primary immune thrombocytopenia (ITP), also called idiopathic thrombocytopenic purpura, is a common hemorrhagic disease. ${ }^{1,2}$ At present, the pathogenesis of ITP is not clear. It is generally believed that, ITP is related to patients' body immunity dysfunction. ${ }^{3}$ About $70 \%$ of patients choose glucocorticoid, immune globulin, splenectomy and immunosuppressor, ${ }^{4}$ where $20 \sim 30 \%$ of patients with ITP turn into rITP due to treatment failure or reoccurrence. ${ }^{5}$ The patients with rITP generally lack sensitivity to hormonotherapy. Even if the high dosage of conventional medicine is used, it is still difficult to 
gain certain curative effect. ${ }^{6,7}$ Therefore, to seek an effective treatment plan for the patients with rITP is the concern of every clinicians. Rituximab as a kind of human-rat chimeric monoclonal antibody has specific recognition ability and can destroy B lymphocyte. ${ }^{8}$ It has significant curative effect on treatment of rITP. In this study, the curative effect of conventional dosage and small dosage of rituximab combined with cyclophosphamide in the treatment of rITP is mainly discussed as follows.

\section{METHODS}

Seventy-eight patients with rITP who were received and treated by Department of Hematopathology in XX Hospital from January 2016 to January 2018 were chosen as the objects of study, including 14 male patients and 64 female patients. Their age was between 16 and 68 , with the median age of 35.5.

\section{Inclusion criteria:}

All patients conformed to diagnostic criteria of rITP;

1. Disease course $\geq 12 \mathrm{~m}$;

2. Platelet count (PLT) $<30 \times 10^{9} / \mathrm{L}$ or hemorrhage;

3. Normal number of megakaryocytes or the increase of megakaryocytes found in bone marrow aspiration, accompanied with dysmaturity.

Exclusion criteria:

1. Children, pregnant women and lactating women;

2. Those sensitive to rituximab or rat protein;

3. Persons infected by hepatitis $B$, hepatitis $C$ virus or HIV;

4. With other autoimmune diseases such as systemic lupus erythematosus, lymphatic proliferative disease, congenital or hereditary thrombocytopenia;

5. Heart, liver and kidney dysfunction. The patients were classified into observation group and control group according to random number table. Each group included 39 patients. All patients had hemorrhage to different degrees.
Both groups had no statistical significance in terms of gender, age, disease course and platelet count $(\mathrm{P}>0.05)$. Both groups had comparability, as shown in Table-I. This study gained patients' informed consent and the approval of Ethics Committee dated September 20, 2018. All patients signed informed consent Form.

Intravenous drip of conventional dosage of rituximab $\left(375 \mathrm{mg} / \mathrm{m}^{2}\right)$ (subpackage approval: GYZZ J20170002, subpackage batch No. of imported medicine: S20170002; S20160029, subpackage enterprise: Shanghai Roche Pharmaceuticals Ltd.) was given for the control group once per week, and the drip duration each time was above $1 \mathrm{~h}$. Besides, intravenous drip of $0.8 \mathrm{~g}$ cyclophosphamide (produced by Jiangsu Shengdi Pharmaceutical Co. Ltd., batch No.: 18022825) was given for the control group once per week, and $2 \mathrm{mg} /(\mathrm{kg} . \mathrm{d})$ cyclophosphamide was taken sequentially. Intravenous drip of small dosage of rituximab $\left(100 \mathrm{mg} / \mathrm{m}^{2}\right)$ was given for the observation group once per week. The same amount of cyclophosphamide was used in the two groups. The treatment duration for both groups was four weeks. To avoid anaphylaxis, separate drip of $5 \mathrm{mg}$ dexamethasone (produced by Tianjin Jinyao Group Co., Ltd., batch No.: 1706252) was given before the drip.

Laboratory examination: Blood routine and four coagulation items were examined twice weekly during the treatment. In case of hemorrhagic tendency, blood routine and four coagulation items should be examined immediately. Before the treatment and four weeks after the treatment, flow cytometry was applied to detect peripheral blood lymphocyte and regulatory $\mathrm{T}$ cells. Quantitative determination of serum immunoglobulin was conducted with immunoturbidimetry. Enzyme linked immunosorbent assay (ELISA) was adopted to test patients' blood biochemistry level.

\section{Observation indexes:}

1. Clinical effect and recurrence rate of both groups were compared. Therapeutic evaluation criteria are as follows. ${ }^{9}$ Complete response:

Table-I: Statistics of general conditions of rITP patients in both groups.

\begin{tabular}{lcccccc}
\hline \multirow{2}{*}{ Group } & No. & \multicolumn{2}{c}{ Gender } & Age & Disease course & Platelet count \\
\cline { 2 - 7 } & & Male & Female & $($ Year $)$ & (year $)$ & $\left(10^{9} / \mathrm{L}\right)$ \\
\hline Observation group & 39 & 14 & 25 & $34.1 \pm 4.1$ & $4.9 \pm 1.1$ & $12.0 \pm 1.5$ \\
Control group & 39 & 14 & 25 & $33.3 \pm 4.2$ & $5.0 \pm 4.2$ & $12.7 \pm 1.4$ \\
t/X & & -- & 0.695 & 0.362 & 1.655 & \\
P & & \multicolumn{2}{c}{$>0.05$} & $>0.05$ & $>0.05$ & $>0.05$ \\
\hline
\end{tabular}


blood platelets rise to $100 \times 10^{9} / \mathrm{L}$ (Test twice more than seven days apart) and there is almost no hemorrhage. Response: blood platelets rise to $30 \times 10^{9} / \mathrm{L}$ (Test twice more than seven days apart) and there is almost no hemorrhage. No response: blood platelets below $30 \times 10^{9} / \mathrm{L}$ or Less than two times of that before treatment (It must be measured twice more than one day apart), and there is no hemorrhage. The cases with complete response and response total to be effective. The computational formula of total effective rate is [(cases with complete response and response)/total cases]. Recurrence: after the effective treatment, the platelet counts declines below $30 \times 10^{9} / \mathrm{L}$ or hemorrhage appear.

2. PLT, HGB content, PT and aPTT of both groups were compared before and after the treatment.

3. The changes in the level of serum immune globulins $\operatorname{Ig} \mathrm{A}, \mathrm{IgM}$ and $\mathrm{IgG}$, and the changes in the level of lymphocytes $\mathrm{CD}^{+}, \mathrm{CD}^{+}$and $\mathrm{CD} 20^{+}$ were compared.

4. The level of Th1, TNF-a, IL-18 and Sc5b-9 were compared.

5. The statistics of total occurrence rate of side effects was conducted for both groups.

Ethical approval: The study was approved by the Institutional Ethics Committee of our hospitals, and written informed consent was obtained from all participants.

Statistical method SPSS 22.0 statistical package was applied for data analysis: Enumeration data were expressed with \%, and measurement data were expressed with $(\mathrm{x} \pm \mathrm{s})$. Chi-square test and $t$ value test were used for inter-group comparison, while one-way analysis of variance was adopted for intra-group comparison. $P<0.05$ means the difference has statistical significance.

\section{RESULTS}

The efficacy rate of observation group was $53.85 \%$, and the effective rate of control group was $64.10 \%$. The difference had no statistical significance $(\mathrm{P}>0.05)$. The recurrence rate of observation group was $5.13 \%$, while the figure was $5.13 \%$ for the control group. The difference had no statistical significance $(\mathrm{P}>0.05)$. Two cases relapsed respectively in both groups, as shown in Table-II.

PLT level of both groups improved significantly after the treatment $(\mathrm{P}<0.05)$. The comparison of HGB level had no statistical significance $(\mathrm{P}>0.05)$. The level of PT and aPTT declined significantly, compared with pre-treatment $(\mathrm{P}<0.05)$. Intergroup comparison of various indexes had no statistical significance $(\mathrm{P}>0.05)$, as shown in Table-III.

The level of $\operatorname{IgM}$ and $\mathrm{CD}_{20} 0^{+}$in the observation group was significantly lower than that of the control group. The level of IgA, IgG, CD3+ and $\mathrm{CD} 4+$ in the observation group was significantly higher than that of the control group $(\mathrm{P}<0.05)$, as shown in Table-IV.

The changes in the level of serum Th1, TNF-a, IL-18 and Sc5b-9 before and after the treatment had no statistical significance $(\mathrm{P}>0.05)$. The inter-group comparison of various indexes had statistical significance $(\mathrm{P}<0.05)$, as shown in Table-V.

Table-II: Clinical effect comparison for rITP patients in both groups [n/ $(\%)]$ comparison of coagulation indicators before and after treatment.

\begin{tabular}{lccccccc}
\hline Group & No. & Significant effect & Good effect & Progress & No effect & Total effective rate & Recurrence rate \\
\hline Observation group & 39 & $13(33.3)$ & $8(20.5)$ & $11(28.2)$ & $7(17.9)$ & $21(53.85)$ & $2(5.13)$ \\
Control group & 39 & $16(41.0)$ & $9(23.1)$ & $8(20.5)$ & $6(15.4)$ & $25(64.10)$ & $2(5.13)$ \\
$\mathrm{X}^{2}$ & & & & & & 0.845 & -- \\
$\mathrm{P}$ & & & & & & $>0.05$ & $>0.05$ \\
\hline
\end{tabular}

Table-III: Comparison of coagulation function and HGB before and after treatment $(x \pm s)(n=39)$

\begin{tabular}{|c|c|c|c|c|c|c|c|c|}
\hline \multirow[t]{2}{*}{ Group } & \multicolumn{2}{|c|}{$\operatorname{PLT}(S)$} & \multicolumn{2}{|c|}{$H G B(g / L)$} & \multicolumn{2}{|c|}{$P T\left(10^{9} / L\right)$} & \multicolumn{2}{|c|}{$a P T T(S)$} \\
\hline & Pre-treatment & Post-treatment & Pre-treatment & Post-treatment & Pre-treatment & Post-treatment & Pre-treatment & Post-treatment \\
\hline Observation group & $12.29 \pm 0.55$ & $85.21 \pm 4.07^{*}$ & $8.97 \pm 0.63$ & $10.58 \pm 0.94$ & $18.64 \pm 1.31$ & $17.18 \pm 1.30^{*}$ & $41.30 \pm 2.62$ & $35.25 \pm 2.43^{*}$ \\
\hline Control group & $12.65 \pm 0.84$ & $87.79 \pm 3.28^{*}$ & $9.15 \pm 0.58$ & $10.92 \pm 0.98$ & $19.28 \pm 1.18$ & $16.74 \pm 1.37^{*}$ & $42.37 \pm 3.00$ & $36.09 \pm 2.28^{*}$ \\
\hline $\mathrm{t}$ & -1.440 & -1.982 & -0.855 & -0.997 & -1.449 & 0.914 & -1.074 & -1.012 \\
\hline $\mathrm{P}$ & $>0.05$ & $>0.05$ & $>0.05$ & $>0.05$ & $>0.05$ & $>0.05$ & $>0.05$ & $>0.05$ \\
\hline
\end{tabular}

Note: comparison before and after the treatment: $\mathrm{P}^{*}<0.05$. 
Table-IV: Comparison of indicators of serum immune globulins and lymphocytes before and after the treatment $(x \pm s)(n=39)$.

\begin{tabular}{|c|c|c|c|c|c|c|}
\hline \multirow[t]{2}{*}{ Group } & \multicolumn{2}{|c|}{$\operatorname{IgA}(g / L)$} & \multicolumn{2}{|c|}{$\operatorname{IgM}(g / L)$} & \multicolumn{2}{|c|}{$\operatorname{Ig} G(g / L)$} \\
\hline & Pre-treatment & Post-treatment & Pre-treatment & Post-treatment & Pre-treatment & Post-treatment \\
\hline Observation group & $0.98 \pm 0.12$ & $0.89 \pm 0.21^{*}$ & $1.65 \pm 0.25$ & $1.72 \pm 0.32 *$ & $10.35 \pm 2.34$ & $9.82 \pm 2.42^{*}$ \\
\hline Control group & $0.97 \pm 0.11$ & $0.42 \pm 0.09^{*}$ & $1.68 \pm 0.27$ & $3.54 \pm 0.75^{*}$ & $10.32 \pm 2.25$ & $4.62 \pm 1.04^{*}$ \\
\hline $\mathrm{t}$ & 0.384 & 12.847 & 0.509 & 13.939 & 0.058 & 12.329 \\
\hline $\mathrm{P}$ & $>0.05$ & $<0.05$ & $>0.05$ & $<0.05$ & $>0.05$ & $<0.05$ \\
\hline Group & CD3+ (109/L) & CD4+ (109/L) & $\mathrm{CD} 20+(109 / \mathrm{L})$ & & & \\
\hline Observation group & $\begin{array}{c}\text { Pre-treatment } \\
1.65 \pm 0.36\end{array}$ & $\begin{array}{c}\text { Post-treatment } \\
1.48 \pm 0.28^{*}\end{array}$ & $\begin{array}{c}\text { Pre-treatment } \\
0.98 \pm 0.23\end{array}$ & $\begin{array}{c}\text { Post-treatment } \\
0.81 \pm 0.29^{*}\end{array}$ & $\begin{array}{c}\text { Pre-treatment } \\
27.9 \pm 3.8\end{array}$ & $\begin{array}{c}\text { Post-treatment } \\
17.1 \pm 2.1^{*}\end{array}$ \\
\hline Control group & $1.64 \pm 0.38$ & $1.18 \pm 0.29^{*}$ & $0.96 \pm 0.25$ & $0.53 \pm 0.20^{*}$ & $28.0 \pm 3.6$ & $16.3 \pm 2.0^{*}$ \\
\hline $\mathrm{t}$ & 0.119 & 4.648 & 0.368 & 4.964 & 0.092 & 16.143 \\
\hline $\mathrm{P}$ & $>0.05$ & $<0.05$ & $>0.05$ & $<0.05$ & $>0.05$ & $<0.05$ \\
\hline
\end{tabular}

Note: comparison before and after the treatment: $\mathrm{P}^{*}<0.05$.

Table-V: Comparison of biochemical indicators before and after the treatment $(x \pm s)(n=39)$

\begin{tabular}{lcccccccc}
\hline \multirow{2}{*}{ Group } & \multicolumn{2}{c}{$T n 1(\%)$} & \multicolumn{2}{c}{$T N F-a(\mu \mathrm{g} / \mathrm{L})$} & \multicolumn{1}{c}{$\mathrm{L}-18(\mathrm{pg} / \mathrm{mL})$} & \multicolumn{2}{c}{$S c 5 b-9(\mathrm{ng} / \mathrm{mL})$} \\
\cline { 2 - 9 } & Pre-treatment Post-treatment & Pre-treatment & Post-treatment & Pre-treatment Post-treatment & Pre-treatment & Post-treatment \\
\hline Observation group & $20.82 \pm 1.49$ & $22.83 \pm 1.90^{*}$ & $72.63 \pm 10.35$ & $62.07 \pm 8.52^{*}$ & $268.90 \pm 57.19$ & $224.00 \pm 39.39^{*}$ & $677.05 \pm 102.71$ & $516.93 \pm 99.39^{*}$ \\
Control group & $20.01 \pm 1.26$ & $21.80 \pm 1.89^{*}$ & $77.62 \pm 8.57$ & $63.86 \pm 9.41^{*}$ & $272.29 \pm 56.89$ & $230.68 \pm 45.28^{*}$ & $675.90 \pm 95.90$ & $538.15 \pm 95.78^{*}$ \\
$\mathrm{t}$ & 2.061 & 1.838 & -1.486 & 0.700 & -0.168 & 0.688 & 0.033 & 0.545 \\
$\mathrm{P}$ & $>0.05$ & $>0.05$ & $>0.05$ & $>0.05$ & $>0.05$ & $>0.05$ & $>0.05$ & $>0.05$ \\
\hline
\end{tabular}

Note: comparison before and after the treatment: $\mathrm{P}^{*}<0.05$.

Liver and kidney damage did not appear for both groups in the treatment period. Based on the statistics of urticarial, fever, shiver, pulmonary infection, dyspnea, alimentary tract hemorrhage and gastrointestinal reaction, the differences in the total occurrence rate of side effects had statistical significance $(\mathrm{P}<0.05)$, as shown in Table-VI.

\section{DISCUSSIONS}

rITP is a kind of autoimmune diseases of the blood system. During the treatment of ITP, the most common medicine is glucocorticoid.
However, some ITP patients are not sensitive to glucocorticoid or resist glucocorticoid. Thus, glucocorticoid treatment failed for some ITP patients, which might be influenced by heat shock protein in ITP patients' peripheral blood mononuclear cells. ${ }^{10}$ The main research progress of rITP lies in the use of rituximab. ${ }^{11} \mathrm{CD} 20^{+}$is an important antigen participating in signal transduction, and regulation of B cell growth and differentiation. Rituximab is human-rat chimeric $\mathrm{CD} 20^{+}$monoclonal antibody for $\mathrm{CD} 20^{+}$molecule on B lymphocyte surface, and it can inhibit B

Table-VI: Comparison of side effects [n/ $(\%)](n=39)$.

\begin{tabular}{lccccccccc}
\hline Group & $\begin{array}{c}\text { Liver } \\
\text { and } \\
\text { kidney } \\
\text { damage }\end{array}$ & $\begin{array}{c}\text { Urti- } \\
\text { carial }\end{array}$ & Fever & Shiver & $\begin{array}{c}\text { Pulmo- } \\
\text { nary } \\
\text { infection }\end{array}$ & Dyspnea & $\begin{array}{c}\text { Alimentary } \\
\text { tract hem- } \\
\text { orrhage }\end{array}$ & $\begin{array}{c}\text { Gastro- } \\
\text { intestinal } \\
\text { reaction }\end{array}$ & $\begin{array}{c}\text { Total occur- } \\
\text { rence rate of } \\
\text { side effects }\end{array}$ \\
\hline $\begin{array}{l}\text { Observation } \\
\text { group }\end{array}$ & 0 & 0 & $1(2.56)$ & $1(2.56)$ & 0 & 0 & 0 & $2(5.13)$ & $4(10.26)$ \\
$\begin{array}{l}\text { Control } \\
\text { group }\end{array}$ & 0 & $2(5.13)$ & $2(5.13)$ & $3(7.69)$ & $1(2.56)$ & $1(2.56)$ & 0 & $2(5.13)$ & $11(28.21)$ \\
$\mathrm{X}^{2}$ & & & & & & & & & 4.287 \\
$\mathrm{P}$ & & & & & & & & & \\
\hline
\end{tabular}


lymphocytes to generate antibody, and reduce the destruction of blood platelets. ${ }^{12}$ Therefore, rituximab is a common medicine to eliminate $B$ cells. ${ }^{13}$ Rituximab as the second-line treatment medicine of ITP is recommended to treat rITP. The patients with ITP (good treatment effect with glucocorticoid) and secondary immune thrombocytopenia have good therapeutic response to rituximab. ${ }^{14} \mathrm{~A}$ study showed that, rITP patients treated with standard dosage of rituximab, and the effective rate of treatment could increase by $70 \%$. Besides, patients' platelet count rose obviously. ${ }^{15}$ The curative effect of standard dosage of rituximab in treatment of ITP can be basically affirmed.

Cyclophosphamide can inhibit cell proliferation, and has no specificity for antigen-sensitized lymphocytes. Cyclophosphamide plays the role of inhibition in cellular immunity and humoral immunity. At present, it has been widely applied in the treatment of autoimmunity and lymphatic systemic diseases. ${ }^{16}$ There has been no unified standard about the therapeutic dosage of rituximab for the adult ITP patients. Currently, standard treatment scheme of ITP with rituximab $\left(375 \mathrm{mg} / \mathrm{m}^{2}\right.$, once per week, use for consecutive $4 \mathrm{w})$ stemmed from lymphoma treatment. But because the number of B cells of ITP patients is far fewer than that of lymphoma patients, after the treatment with standard dosage of rituximab, CD20 cells in peripheral blood almost disappear, which increases the infection chance. ${ }^{17}$ At present, the most important problem perplexing doctors and patients is how to control the blood platelet level of rITP patients who have no effect on hormone or depend on hormone. Therefore, the clinical effect of rituximab combined with cyclophosphamide in the treatment of rITP patients, and the optimal dosage of rituximab were investigated in this paper.

In this study, after rITP patients were treated by rituximab combined with cyclophosphamide, peripheral blood lymphocyte $\mathrm{CD}^{2} 0^{+}$was negative, which proves that rituximab gives play to the good effect of scavenging agent for B lymphocytes, and the decreasing function for ITP autoantibody, thus further relieving the destruction to blood platelets. Patients' PLT and HGB level rose significantly compared with pretreatment, while PT and aPTT level significantly declined, compared with pre-treatment. This indicates that, after the treatment with the scheme, platelet count, hemoglobin count and coagulation function of both groups recovered effectively, and could reach the satisfying shortterm curative effect. The level of IgM and CD20 ${ }^{+}$ in the observation group reduced significantly, compared with the control group. The level of IgA, IgG, CD3+ and CD4+ rose significantly, compared with the control group. This means that, after the treatment, immune system damage of the patients in the observation group is obviously lower than that in the control group. Standard dosage of rituximab may damage the functions of immune cells and normal B lymphocytes, and increases the potential risk of serious infection. Cell factors of both groups such as Th1, IL-18, TNF-a and sC5b-9 declined obviously, which indicates that rituximab combined with cyclophosphamide can improve patients' immunologic disorder and has significant curative effect on rITP.

The treatment safety of rituximab combined with cyclophosphamide is positive. The occurrence rate of side effects in the observation group is obviously lower than that in the control group. This means the low dosage of rituximab is safer and more effective. In the treatment process, rituximab and cyclophosphamide had certain influence on patients' peripheral blood leucocyte, liver and kidney functions. Traditional dosage of rituximab may cause patients' humoral immunity is damaged for a long term, and even serious infection and reactivation of hepatitis B virus may be caused. To reduce the treatment risk, nucleoside meducines such as lamivudine may be applied preventively. ${ }^{18}$

\section{CONCLUSION}

Small dosage of rituximab combined with cyclophosphamide can significantly improve clinical symptoms of rITP patients, and has good curative effect, without serious untoward effect. So, the treatment scheme has high safety. However, the medicine is expensive. Thus, the researchers tried to apply small dosage of rituximab combined with cyclophosphamide to treat rITP. It was found that, the curative effect was close to the standard dosage of rituximab combined with cyclophosphamide. So, this treatment scheme deserves to be promoted and encouraged.

Declaration of conflicting interest: None.

Funding: None. 


\section{REFERENCES}

1. Thota S, Kistangari G, Daw H, Spiro T. Immune thrombocytopenia in adults: An update. Cleve Clin J Med. 2012;79(9):641-650. doi: 10.3949/ccjm.79a.11027

2. Rocha AM, Souza C, Rocha GA, de Melo FF, Clementino NC, Marino MC, et al. The levels of IL-17A and of the cytokines involved in Th17 cell commitment are increased in patients with chronic immune thrombocytopenia Haematologic. 2011;96(10):1560-1564. doi: 10.3324/ haematol.2011.046417

3. Zheng R, Xie S, Niyazi S, Lu X, Sun L, Zhou Y, et al. MetaAnalysis of the Changes of Peripheral Blood T Cell Subsets in Patients with Brucellosis. J Immunol Res. 2018,17(5):Article ID 8439813. doi: 10.1155/2018/8439813

4. Yonghao G, Jin X, Jun L, Pumei D, Ying Y, Xiuhong F, et al. An epidemiological serosurvey of hepatitis $B$ vaccination in central China. Int J Infect Dis. 2015;40:75-80. doi: 10.1016/j. ijid.2015.10.002

5. Kashiwagi H, Omiyama Y. Pathophysiology and management of primary immune thrombocytopenia. Int J Hematol. 2013;98(1):24-33. doi: 10.1007/s12185013-1370-4

6. Neunert C, Lim W, Crowther M, Cohen A, Solberg L Jr, Crowther MA. The American Society of Hematology 2011 evidence-based practice guideline for immune throm bocytopenia. Blood. 2011;117(16):4190-4207.

7. Rinott N, Mashiach T, Horowitz NA, Schliamser L, Sarig G, Kerenpolitansky A, et al. A 14-year experience in the management of patients with acquired immune thrombotic thrombocytopenic purpura in Northern Israel. Acta Haematol. 2015;134(3):170-176. doi: 10.1159/000371867

8. Han HJ, Lu YW, Xia RX. Clinical efficacy and safety of rituximab combined with fludarabine and cyclophosphamide for treatment of chronic lymphocy- tic leukemia. J Exper Hematol. 2016;24(1):25. doi: 10.7534/j. issn.1009-2137.2016.01.005

9. Lian Bai. Evaluation of therapeutic effects of three schemes for severe ITP. Jilin Med J. 2017;38(12):2330-2331.

10. Qingchi L, Weihai W, Dayong W, Xinwang F, Yahui M, Jianying L, et al. Clinical observation on the treatment of childhood refractory idiopathic thrombocytopenic purpura with Dihuang Zhixue Capsule. Chin J Integr Med. 2008;14(2):132-136. doi: $10.1007 /$ s11655-008-0132-2
11. Ghanima W, Godeau B, Cines DB, Bussel JB. How I treat immune thrombocytopenia: the choice between splenectomy or a medical therapy as a second-line treatment. Blood, 2012;120(5):960-969. doi: 10.1182/ blood-2011-12-309153

12. Gall B, Yee A, Berry B, Birchman D, Hayashi A, Dansereau $\mathrm{J}$, et al. Ritximab for management of refractory pregnancyassociated immune thrombocy topenic purpura. J Obstet Gynecol Can. 2010;32(12):1167-1171. doi: 10.1016/S17012163(16)34741-7

13. Czuczmn MS, Gregory SA. The future of $\mathrm{CD}_{20}$ monoclonal antibody therapy in B-cell malignancies. Leuk Lymphoma. 2010;51(6):983. doi: 10.3109/10428191003717746

14. Godeau B. B cell depletion in immune thrombocy topenia. Semin Hematol. 2013;50(Suppl 1):S75-S82.

15. Audia S, Rossato M, Trad M, Samson M, Santegoets K, Gautheron A, et al. B cell depleting therapy regulates splenic and circulating $\mathrm{T}$ follicular helper cells in immune thrombocytopenia. J Autoimmun. 2017;77(15):89-95. doi: 10.1016/j.jaut.2016.11.002

16. Provan D, Stasi R, Newland AC, Blanchette VS, Boltonmaggs $\mathrm{P}$, Bussel JB, et al. International consensus report on the investigation and management of primary immune thrombocytopenia. Blood. 2010;115(2):168-186. doi: 10.1182/blood-2009-06-225565

17. Grace RF, Bennett CM, Ritchey AK, Jeng M, Thornburg $\mathrm{CD}$, Lambert MP, et al. Response to steroids predicts response torituximab in pediatric chronic immunethrom bocytopenia. Pediatr Blood Cancer. 2012;58(2)221-225. doi: $10.1002 / \mathrm{pbc} .23130$

18. Marangon M, Vianelli N, Palandri F, Mazzucconi MG, Santoro C, Barcellini W, et al. Rituximab in immune thrombocytopenia: gender, age, and response as predictors of long-term response. Eur J Haematol. 2017;98(4):371-377. doi: 10.1111/ejh.12839

\section{Authors' contributions:}

ZW \& HY designed this study and significantly revised the manuscript.

YR, ML \& WH performed this study and drafted the manuscript, are responsible for integrity of research. 